\title{
Bridging the gap: A Collaborative Approach to Rural Sustainability
}

\author{
Elisha Purchase
}

\begin{abstract}
In August 2013, the Eastern Ontario Warden's Caucus (EOWC) produced a series of whitepapers that address municipal affordability in Eastern Ontario and the financial sustainability of local governments. With costs drastically outpacing population growth, rural municipalities have few means to bridge the gap. The white papers report that municipal operating budgets have increased by $65 \%$ over a ten year period, while population growth rose $13 \%$. The factors driving costs are the same for each municipality, which supports the need to increase efficiencies through a regional approach on cost sharing. This same approach needs to be considered in economic development as communities continue to compete for investment from the same market place.
\end{abstract}

This paper proposes that regional collaboration will result in economic sustainability. Economic and municipal strategies need to reinforce collaborative strategies through the development of a regional approach that shares costs and secures partnerships to deliver services and contain these costs. Short term actions should include developing an economic development strategy for Eastern Ontario, securing funding for infrastructure maintenance, and forming a task force that will investigate ways to contain infrastructure costs.

Keywords: Collaboration, economy, regional, sustainability, growth

\section{Introduction: A collaborative approach}

Collaboration: working with each other to complete a task and to achieve shared goals (Collaboration, 2014). Taking a collaborative approach is a well-developed concept increasingly being practised in today's economy. Businesses are working together to create a stronger presence and enhance their ability to succeed. Communities are taking a regional approach to focus on similarities that will further attract investment and ultimately create a stronger economy.

Today's economic climate is affected by several factors. The level of competition being faced by businesses and communities has never been greater as the economy continues to climb out of a global recession. At times this climb feels like a scramble. The government has implemented a number of short term fixes, but the question needs to be asked, are these short term fixes leading to long term solutions? Municipalities continue to compete for investment without the necessary competitive advantages that are promoted and sold to consumers. Rural municipalities in 
particular are significantly challenged as they rely largely on residential tax revenues to fund operations.

Major challenges are being faced by rural Ontario and a greater need for regional collaboration can be justified to help municipalities succeed in reaching their goals and creating further economic growth. This paper will examine the need for greater regional collaboration and will address the major challenges being faced by municipalities, specifically in Eastern Ontario. Also discussed are best practices in collaboration that help overcome these obstacles, and what long term strategies need to be in place in order to strengthen the economic climate and create sustainability.

\section{The growth problem}

Whether examining a metropolitan centre facing rapid growth, or a rural area lacking it, growth is a challenge faced in economic development. Ontario's population is expected to increase by 3.9 million people by 2036 and most of this population growth will be in the Greater Toronto Area (Firth, 2013). While large urban centres deal with how to address the population influx, rural Ontario has the opposite problem. Rural areas across the province have witnessed a decline of industry, closure of schools, and decrease in services; the cause of this migration to large urban centres and aging. These trends have directly impacted the growth challenge in much of Eastern Ontario.

According to a report released by the Rural Ontario Institute in June 2013, there has been virtually no growth recorded in rural Ontario in the last eight years (Rural Ontario Institute, 2013). This is troubling because population growth has been the traditional indicator of development; an increase indicates that jobs are being created and that the area is an attractive place to live and do business. This report identifies that the population in Ontario's rural areas grew for ten consecutive years from 1996 to 2006, but there has been little change since. Meanwhile, the urban population has grown more than $1.2 \%$ annually during the same period (Rural Ontario Institute, 2013b). Rural Ontario is experiencing no net growth, which for Eastern Ontario means little growth based on the rural-urban mix. These statistics will hopefully give rural regions the desire to lead with new and innovative strategies that attract new residents and investment.

Businesses are operating in an economy where the level of competition in the marketplace continues to rise. Municipalities in Eastern Ontario are no different; each community is essentially working to achieve the same goals as private businesses. While businesses strive to increase profits to support business growth, municipalities work to attract investment that will create a more supportive tax base. Defined as, "the effort of two or more parties acting independently to secure the business of a third party by offering the most favorable terms" (Competition (economics), 2014), competition at all levels continues to challenge growth. Major growth obstacles are evident, one of which is demographics. It is well known that rural 
communities have an older age demographic. Youth and young families are seeking a lifestyle found in urban areas, seduced by better employment opportunities, cultural diversity, educational facilities, and certain conveniences that do not exist in rural communities. Ontario's senior population, representing ages 65 and older, make up $20 \%$ of the provincial population and statistics show that between 1996 and 2012, the number of seniors in Ontario grew at an average rate of 2.6\% (Rural Ontario Institute, 2013a). Growth in the senior population has important implications as it indicates an increase in the demand for many services. For municipalities, the demand for services by seniors often equates to higher costs.

When examining Ontario's aging population, it is important to note trends in the working age population. As the baby-boomer demographic ages, the province must prepare for a potential labour market shortage. A situation is being created that has more individuals retiring than young adults entering the work force. This statement is particularly true at the rural level. Summarizing a report provided by Rural Ontario; a deficit in the balance of incoming youth versus retirees is more evident in rural areas of the province than urban ones, resulting in a greater number of potential labour market shortages (Rural Ontario Institute, 2013c).

\section{Bridging the gap}

Looking outside of economic development, the need for municipalities to look at regional collaboration as it relates to all municipal services is essential. In August of 2013, the Eastern Ontario Warden's Caucus (EOWC) released a series of white papers on municipal affordability with a focus on financial sustainability. This series paints an alarming picture for rural Ontario, with data that illustrates the relationship and the current gap between municipal costs and the revenue being generated.

In summary, the EOWC report discussed the total operating expenditures for rural Eastern Ontario. From 2000 to 2011, operating costs increased by a staggering $65 \%$ over the eleven year period. This significant increase in municipal spending weighs heavily on the tax base, as population growth during this same period was a mere $13 \%$. Based on these figures, projections show continued increases over the next ten years, with costs projected to reach $\$ 2.24$ billion by 2020 , an additional increase of $\$ 440$ million from 2011. This increase means that through this decade, operating budgets for local governments in the region's rural areas will rise by roughly $\$ 50$ million (EOWC, 2013b).

The increase in municipal operations can be explained as easily as supply and demand; if demand increases and supply remains unchanged, a shortage occurs, leading to a higher price (Supply and Demand, 2014). In relation to municipal operations, as the need for and cost of services (demand) increases and population paying taxes (supply) remains the same, a shortage occurs, leading to a higher price (tax rate). This will continue to create a larger gap between the municipal operating budget and the current tax revenue. This is not a ratio that can continue to widen if municipalities are to operate sustainably. 
In addition to measuring cost increases against the flat growth rate, this report identifies the greatest drivers of increased costs (summarized in Figure 1).

Figure 1: The biggest drivers of increased costs by 2020.

Transportation Protection

Adapted from: EOWC (2013). Dollars and Sense: Managing Municipal Affordability. Retrieved from http://www.haliburtoncounty.ca/wp-content/uploads/2013/09/Financial-Sustainability-UpdateManaging-Municipal-Affordability-Panel.pdf

The four services outlined in Figure 1 represent over half of the total increase in municipal operating budgets and are significant barriers to rural municipalities. Transportation is the biggest challenge as municipalities have struggled with a $93 \%$ spending increase on roads and bridges over the past decade. Still, municipalities are spending less than half of what is needed on capital infrastructure investment in the Eastern Ontario region (EOWC, 2013a). A significant threat is the limited capacity to raise taxes, which does not create a sustainable tax model. The modest gain in growth is a direct result of the region's limited ability to stimulate development. The EOWC report recognizes that the region is comprised of a $90 \%$ residential tax base. With $10 \%$ commercial and a minimal $25 \%$ of fully taxable land, municipalities have few means to bridge the gap that has been created It is imperative that the region investigate collaborative opportunities now as these rising costs cannot be met by communities alone (EOWC, 2013b).

\section{Regional collaboration}

Ontario's rural communities struggle to make ends meet financially, and they also struggle to stand out to potential residents and investors in today's competitive economy. Communities that are located in close proximity to each other usually have similar access to infrastructure, labour pools and markets. Many communities have the same competitive advantages and key sectors that their neighbours have; therefore how can they differentiate themselves in a very crowded market place? Many communities are targeting the same markets and marketing the same message, and unfortunately few are doing this collectively. Every community wants to be, "a great place to live, work and play!" Given the limitations to place-based competitiveness and innovation, communities need to leverage marketing opportunities that differentiate themselves and capture the interest of their target markets. If communities invest their limited resources into marketing the same message to the same audience without any collective strategy, they will continue to see little return from their investment. 
Target marketing and collaboration are two strategies being recognized and implemented at regional levels. If rural areas understand the current market mix and their customer base, andmost importantly - work together, balancing the demographics will be a feasible objective. This strategy will promote the collective assets of a region as a great place to invest and result in the attraction of markets that will contribute to a sustainable rural Ontario.

All levels of government, communities and business operators are recognizing the value of this strategy and are adopting collective approaches in order to remain strong and competitive. This approach is certainly not new to economic development. For example, regional initiatives have evolved to focus on more specific goals and have branched out to new sectors of development that are less traditional. Municipalities throughout Ontario are recognizing the benefits of working together to attract investment and understand that, "If a team is to reach its potential, each player must be willing to subordinate his personal goals to the good of the team" (Wilkinson, n.d.). Rather than describing neighboring municipalities as competitors, they are recognizing them as partners, which is a huge change from the traditional competitive or zerosum approach.

An article titled "Banding Together, Branding Together"1 recognizes the strength created through collaborative efforts (Burghard, 2013). This article suggests that two key questions need to be asked when considering collaborative initiatives: when does it make sense to band together, and is it a good idea? It is important to realize that collaboration is a strategic choice made to achieve a specific objective and is not necessarily the right choice for every situation. The purpose of collaboration is to leverage each organization's individual resources to enhance a common objective. Collaboration is not an effective approach if there is little in common among the stakeholders. Once a collaborative effort is underway, the key players need to bring their complementary strengths to the table in order to achieve superior results (Burghard, 2013).

Municipal initiatives are being planned around three key pillars of rural economic development: business, tourism and living. Each of these pillars is essential for sustaining economies. Rural economic strategies focus on the same principles they build from existing assets and develop new opportunities in order to attract and retain a diverse population base, expand existing economic development efforts to support business growth, and take advantage of tourism potential to create further economic gain from visitor attraction. These strategies support one another to create a stable and sustained economy.

In examining rural communities across Eastern Ontario, there are simply not enough characteristics that differentiate the number and quality of assets and services being offered. By operating in silos, individual organizations have little opportunity to create a sustainable economy. This challenge has been recognized and economic development professionals are

\footnotetext{
${ }^{1}$ based on an IEDC report of the same name
} 
working together to design investment strategies that market their community assets. This will prove to be very important in rural communities with limited resources.

The Bay of Quinte Region is one region in Eastern Ontario that is "banding and branding" together to further its economic growth. For example, tourism in this area is being driven by Bay of Quinte Tourism, a flourishing organization promoting tourism opportunities across the region. Tourism is now one of three products branded under the recently organized Bay of Quinte Region (2012). This initiative has evolved by focusing on the same three regional pillars (business, tourism and living) that are emphasized in strategic planning at a local level. Based on that successful tourism model, the Bay of Quinte group secured a partnership with the Quinte Economic Development Commission (QEDC). With a strong understanding of the strength in support and partnerships, QEDC is an economic development agency that supports local industry with strategic planning, financing, training and site selection (Quinte Economic Development Commission, 2014). As a key partner in the Bay of Quinte initiative, the QEDC is now operating as Bay of Quinte Business, which supports the goal of collaboration between the primary pillars of economic development.

The third and most recent development supporting this initiative is the creation of Bay of Quinte Living, an organization promoting the unique attributes of the region as a place to live through collaboration and community partnerships (Bay of Quinte Living, 2013). Regional collaboration is extremely evident in this alliance, as the group represents municipal partners, realtors, educators, health providers and the construction industry across the region. This group replicated the same model as Bay of Quinte Tourism, a model which has driven success in tourism across the region.

While the above organizations operate on funding from municipal partners and generate revenue from specific project deliverables, the key contribution that has sustained them is stakeholder support. For Bay of Quinte Tourism, stakeholder support is provided as funds from tourism operators, specifically accommodators; a percentage from overnight accommodations is granted back to the organization to support the attraction of travelers to the region. Like their tourism counterpart, it is the goal of Bay of Quinte Living to receive support from stakeholders in the region who benefit from the attraction of new residents. If dollars can be generated from the sale of homes, this will reinforce the creation of a sustainable model that will support population growth. With resources and leadership in place, this collaborative model could act as a pilot and be tested across other regions as a tool for rural development.

\section{Recommendations}

The purpose of the EOWC report on financial sustainability is to look at challenges shared across the region in order to find efficiencies. One viable solution to creating a sustainable model for economic growth is developing long term partnerships and strategies that result in collaboration across the region. Based on the information collected, short term actions should include 
developing an economic development strategy for Eastern Ontario and forming a task force that will investigate ways to contain infrastructure costs, as well as securing targeted funding to maintain infrastructure.

Economic and municipal strategies need to reinforce collaborative strategies through the development of a regional approach that shares costs and secures partnerships to deliver services and contain these costs. For example, the region needs to play a stronger role in exploring ways to make municipal services more efficient, and provide leadership in controlling cost measures. It should also investigate the amalgamation of services where appropriate, and develop economically-focused relationships that stimulate growth in the region's tax base (EOWC, 2013b).

A change in the approach to cost sharing will significantly change the long term forecast for municipal operations. In order to create sustainable rural economies, regions need to create a product or brand that results in preference. A strategy that reflects rural culture and connects to urban markets will start to bridge the gap between rural and urban. This is not achievable unless explored regionally.

This paper has been generated with data from the Eastern Ontario region; however the recommendations being addressed should be applied across the province as most of rural Ontario faces the same challenges. In order for change to occur, the Province of Ontario needs to play a strategic role and act on the major issues that will relieve pressure at the municipal level. This could include compensation for non-taxable lands, creating infrastructure funds designed specifically for rural and remote areas, streamlining provincial reporting requirements, and investigating methods to further contain the most significant drivers of increased costs (EOWC, 2013b). These same measures need to be investigated by the Federal Government.

\section{Conclusion: Paving the way to sustainability}

There is a pressing need for new approaches to rural economic development, drawing on a stronger sense of competitiveness in the global economy and effective collaborations. Each rural region needs a distinctive strategy that integrates rural economies with nearby urban centers, and a strategy that reflects its unique strengths and particular mix of clusters (Institute for Strategy and Competitiveness, n.d.). Based on the shared challenges identified, upper and lower-tier municipalities should aim to improve their viability through strategic activities, regional collaboration, and capacity building. If this approach is taken collectively, individual stakeholders and regions will benefit from improved municipal service delivery and governance, a greater ability to respond to priorities while building strong relationships, investment attraction, and effective collaborative activities that result in strengthened communities (Alberta Municipal Affairs, 2014). 
These priority outcomes could significantly impact the level and type of growth taking place in rural areas, and contribute to closing the current gap between rising costs and a primarily residential tax base. As previously referenced, this gap is a direct outcome of supply and demand. Municipalities are seeing an increase in demand, and for supply to remain unchanged, a higher price must be paid to sustain the same level of service. Based on the projections that have been made for the next decade, this is not an equation that can be sustained much longer and a change in approach is necessary. These rising costs cannot be met by the limited rural property tax base. If demand continues to increase and supply remains unchanged, a shortage will occur and services will be affected due to a cap in price. In recent years this outcome has led to municipal amalgamation. This has a significant impact on the level of service being received by tax payers, and rural areas of amalgamated municipalities are still struggling with the impact today. Innovative and collaborative approaches to cost sharing can create a detour from this scenario and alternatively lead to growth and future development.

It is clear that collaboration plays a critical role in rural economic development. When Ontario established tourism regions across the province, it was with the intent of paving the way for a stronger, more competitive and sustainable industry (Ministry of Tourism, Culture and Sport, 2014). These words visibly define why collaboration is such an important element of economic development.

\section{Author Biography}

Elisha Purchase, Manager of Economic Development for the Municipality of Brighton, is responsible for stimulating growth and securing new opportunities. Prior to this position, she was the Economic Development Officer for the Township of Stirling-Rawdon. Elisha is a graduate from Loyalist College and is working towards her economic development designation through the University of Waterloo.

\section{References}

Alberta Municipal Affairs (2014). Regional Collaboration Program. Retrieved from http://municipalaffairs.alberta.ca/MC_regionalcollaborationprogram.cfm

Bay of Quinte Living (2013). About Us. Retrieved from http://living.bayofquinte.ca/?page_id=237

Bay of Quinte Region (2012). Bay of Quinte Region Home Page. Retrieved from http://bayofquinte.ca/

Burghard, E. (2013). Banding Together, Branding Together. SBA Blog. Retrieved from http://strengtheningbrandamerica.com/blog/2013/10/banding-together-branding-together/ 
Collaboration. (2014, February 6). In Wikipedia, The Free Encyclopedia. Retrieved from http://en.wikipedia.org/w/index.php?title=Collaboration\&oldid=594214709

Competition (economics). (2014, January 27). In Wikipedia, The Free Encyclopedia. Retrieved from http://en.wikipedia.org/w/index.php?title=Competition_(economics)\&oldid=592696639

Eastern Ontario Wardens' Caucus (2013a). Dollars and Sense: Managing Municipal Affordability. Retrieved from http://www.haliburtoncounty.ca/wpcontent/uploads/2013/09/Financial-Sustainability-Update-Managing-Municipal-AffordabilityPanel.pdf

Eastern Ontario Wardens' Caucus (2013b). Municipal Affordability. From Financial Sustainability of Local Governments in Eastern Ontario. Retrieved from http://www.eowc.org/en/futuredirections/resources/MunicipalAffordabilityEOWCWhitePaperV5August182013.pdf

Firth, M. (2013, October 19). Goodbye, hometown: Small-town Ontario struggles to stay alive. The London Tribune. Retrieved from http://www.lfpress.com/2013/10/17/goodbye-hometownsmall-town-ontario-struggles-to-stay-alive

Institute for Strategy and Competitiveness (n.d.). Competition and Economic Development. Retrieved from http://www.isc.hbs.edu/economicdevelopment.htm

Ministry of Tourism, Culture and Sport (2014). Regions. Retrieved from http://www.mtc.gov.on.ca/en/regions/regions.shtml

Quinte Economic Development Commission (2014). Support Services. Retrieved from http://www.quintedevelopment.com/support-services/

Rural Ontario Institute (2013a). Growth in number of seniors. Focus on Rural Ontario, 1(8). Retrieved from

http://www.workforcedevelopment.ca/sites/default/files/Growth\%20in\%20number\%20of\%20sen iors\%20-\%20July\%202013.pdf

Rural Ontario Institute (2013b). Rate of growth of non-metro population. Focus on Rural Ontario, 1(3). Retrieved from http://ruralontarioinstitute.ca/file.aspx?id=18162300-1243-4e91a991-459291e3d45f

Rural Ontario Institute (2013c). Working age population. Focus on Rural Ontario, 1(10). Retrieved from http://ruralontarioinstitute.ca/file. $\operatorname{aspx}$ ?id=6b42f63c-6312-4c2e-8d07$\underline{\text { f9bb9e455491 }}$

Supply and demand. (2014, March 3). In Wikipedia, The Free Encyclopedia. Retrieved from http://en.wikipedia.org/w/index.php?title=Supply_and_demand\&oldid=597943408 
Wilkinson, B. (n.d.). Teamwork Quote. Retrieved from

http://www.inspirationalspark.com/teamwork-quotes.html 